\title{
Climbing the corporate ladder and within-person changes in narcissism: Reciprocal relationships over two decades
}

\author{
Bart Wille $^{1}$, Joeri Hofmans ${ }^{2}$, Filip Lievens ${ }^{3}$, Mitja D. Back ${ }^{4}$, and Filip De Fruyt ${ }^{1}$ \\ ${ }^{1}$ Ghent University, Belgium \\ ${ }^{2}$ Vrije Universiteit Brussel, Belgium \\ ${ }^{3}$ Singapore Management University, Singapore \\ ${ }^{4}$ University of Münster, Germany
}

\begin{abstract}
Accepted version of paper published in Journal of Vocational Behavior. This paper is not the copy of record and may not exactly replicate the final, authoritative version of the article.

Date of acceptance: August 26, 2019.

Correspondence concerning this article should be addressed to Bart Wille, Department of Personnel Management, Work and Organizational Psychology, Ghent University, H. Dunantlaan 2, 9000 Gent, Belgium;

Email: bart.wille@ugent.be
\end{abstract}




\begin{abstract}
Prior research demonstrated that narcissism fosters the attainment of higher managerial ranks in organizations. However, it is not known whether climbing the corporate ladder also fosters the development of narcissism over time. Whereas prior work consistently adopted a unidirectional perspective on narcissism and career attainment, this study presents and tests a bidirectional perspective, incorporating long-term development in narcissism in relation to and in response to long-term upward mobility. To this end, a cohort of highly educated professionals was assessed three times over a 22-year time frame. Extended latent difference score modeling showed that, over the entire interval, within-person changes in narcissism were positively related to withinperson changes in upward mobility. This was in line with our first hypothesis which described a positive co-development between both processes over time. However, when reciprocity was analyzed in a time-sequential manner, i.e. from the first career stage to the second, we found more support for narcissism predicting later upward mobility (Hypothesis 2) than for the reverse effect from mobility to later change in narcissism (Hypothesis 3). Moreover, this effect from upward mobility to subsequent change in narcissism was negative, indicating that higher career attainment during the first career stage inhibited (rather than fostered) subsequent growth in narcissism. In sum, these results indicate that narcissism continues to demonstrate room for development over the course of people's careers. However, future research is needed to further clarify the exact nature of the effects that career experiences such as upward mobility have on this developmental process.
\end{abstract}

KEYWORDS: narcissism; managerial level; career attainment; personality development 


\section{Climbing the Corporate Ladder and Within-Person Changes in Narcissism:}

\section{Reciprocal Relationships Over Two Decades}

Although it is commonly believed that in organizations 'the cream rises to the top', research also shows that climbing the corporate ladder is associated with dark side, derailed, or aberrant personality tendencies, and particularly with narcissism (e.g., Ahmetoglu et al., 2016; Grijalva, Harms, Newman, Gaddis, \& Fraley, 2015; Harms, Spain, \& Hannah, 2011; Wille, De Fruyt, \& De Clercq, 2013). Moreover, the prevalence of narcissistic executives appears to have increased over the last two decades, which has sparked scholarly interest in the consequences of this dark personality trait in managers (Buyl, Boone, \& Wade, 2019; Chatterjee \& Hambrick, 2007, 2011; Engelen, Neumann, \& Schmidt, 2016; Martin, Cote, \& Woodruff, 2016). Indeed, accumulating evidence shows that narcissists' risky strategies and investments (e.g., Wales, Patel, \& Lumpkin, 2013; Zu \& Chen, 2015) can significantly endanger organizations' success in the long run.

Despite this recent awareness, relatively little is known about the directionality of the relationship between narcissism and career attainment. Is narcissism more common for people higher on the corporate ladder because they are selected into upper echelons because of their narcissism-related traits? Or do experiences associated with the attainment of these higher-level roles foster the development of narcissistic tendencies? Disentangling these alternative explanations is critical if one wishes to comprehensively understand narcissism in corporate settings and take adequate measures to manage and control it. For instance, if narcissism grows as people climb up the corporate ladder, then screening out people with high levels of this trait when selecting for managerial functions (e.g., Engelen et al., 2016) is a relevant but insufficient measure. In this particular case, monitoring levels of narcissism over time, especially when people have experienced upward transitions, is equally important. 
Such an inquiry into within-person changes in narcissism throughout people's careers first requires a new conceptual perspective on narcissism in which the trait is no longer seen as "set like plaster" once adulthood is reached (e.g., Costa \& McCrae, 1994). Importantly, there is increasing awareness in the organizational behavior (e.g., Woods, Lievens, De Fruyt, \& Wille, 2013), management (e.g., Tasselli, Kilduff, \& Landis, 2018) and careers (e.g., Woods, Wille, Wu, Lievens, \& De Fruyt, 2019) literatures that personality is not unchangeable, but instead continues to develop throughout the entire life course. Moreover, the bulk of research on personality development documents a dynamic interplay between personality and outcomes in different life domains (Specht, Egloff, \& Schmukle, 2011). That is, personality traits not only predict longterm outcomes, but are at the same time influenced by exactly these same outcomes, a mechanism referred to as the corresponsive principle (Caspi, Roberts, \& Shiner, 2005; Roberts \& Caspi, 2003). In this regard, an - until now untested - explanation for the positive association between narcissism and career attainment might be that, after being selected into higher level jobs, people's narcissistic tendencies are further amplified as a result of professional successes.

There is currently a glaring lack of knowledge on the developmental trajectories of narcissism in adulthood, let alone on the specific conditions that may influence it (Grijalva \& Harms, 2014; Orth \& Luciano, 2015; Tasselli et al., 2018). With regard to narcissism development, some preliminary research has demonstrated age differences in narcissism, showing that older people tend to score lower on narcissism compared to younger people (Foster, Campbell, \& Twenge, 2003; Roberts, Edmonds, \& Grijalva, 2010). However, the cross-sectional nature of these data does not allow firm conclusions about intraindividual change and development of this construct across time. Instead, such age differences have mainly been used to inform the debate on the (non-)existence of generational differences in narcissism (e.g., Roberts et al., 2010; Trzesniewski, Donnellan, \& Robins, 2008a; 2008b). In addition to this cross- 
sectional work, and more relevant to the current study, a handful of investigations have looked at within-person changes in narcissism using longitudinal designs in which participants are tracked across several years during young adulthood (i.e., under age 30) (Carlson \& Gjerde, 2009; Grosz et al., 2019; Orth \& Luciano, 2015). Across all three studies, virtually no mean-level intraindividual change in narcissism was observed during early adulthood.

Turning to the conditions that may influence narcissism development, Grosz et al. (2019) considered 30 discrete life events that may explain differences between people in intraindividual change in narcissism, including some events that relate to people's work life (e.g., starting a new job). However, much of this work was exploratory in nature and it was conceptually unclear how several of the considered life events are related to narcissism development. Moreover, a notable limitation of this approach was that the life events were only assessed once at the end of the time period, which makes it impossible to disentangle whether life events caused changes in narcissism, or changes in narcissism caused life events to occur.

Against this background, the current paper aims to contribute to this literature in three distinct ways. First, this work presents a unique longitudinal investigation of narcissism, looking at change and stability of this construct across a large and meaningful period of time, namely the first twenty years of people's professional careers. Unlike previous longitudinal research in this area, the current study is not restricted to early adulthood, but instead considers a broader age range to get a more comprehensive picture of narcissism development in adulthood (i.e., from age 22 to 44). Second, the present study zooms in on one theoretically relevant catalyst of narcissism development during this stage of life, namely mobility on the corporate ladder. Given that narcissism and upward mobility are both connected to the higher-order motive of getting ahead (Grijalva \& Harms, 2014) it seems warranted to investigate the co-development of these two processes across a long and meaningful period of time. Third, little is currently known about the 
temporal dynamics of the way in which narcissism development influences and is influenced by life experiences, in particular career development. By scrutinizing the reciprocal relationships between narcissism and career attainment in a time-sequential manner, i.e. from one time interval to the other, this paper investigates how within-person change in one construct (i.e., hierarchical rank within an organization) during one's initial career stage influences within-person change in the other construct (i.e., narcissism) during the next career stage and vice versa.

From a practical perspective, our results can inform organizations about potential sideeffects of upward mobility. Obtaining insight into the developmental properties of narcissism is important because the highest levels of narcissism have been related to various unethical and exploitative organizational behaviors, interpersonal deficits, and overall leader ineffectiveness (see Buyl et al., 2019; Campbell et al., 2011; Grijalva \& Harms, 2014; Grijalva et al., 2015; O’Reilly, Doerr, \& Chatman, 2018).

\section{THEORETICAL BACKGROUND}

We begin our investigation by describing the main theoretical mechanisms through which (a) narcissism enhances career attainment and (b) work experiences influence personality development. Next, we extend existing theory by explaining how narcissism and career attainment may foster each other over time, ultimately culminating in a bidirectional perspective on narcissism and career attainment.

\section{Narcissism and Its Predictive Effects on Higher Career Attainment}

Although different conceptualizations of narcissism have been adopted in careers, organizational behavior and management literatures, a common thread running through these definitions is that narcissism entails characteristics such as a grandiose self-concept, feelings of superiority, self-centeredness, and sense of entitlement (e.g., Ackerman et al., 2011; Morf \&

Rhodewalt, 2001). Given that some of the hallmark characteristics associated with narcissism are 
associated with the motive to "get ahead" (Grijalva \& Harms, 2014), much of this work in the organizational sciences has studied narcissism in relation to ascendancy up the corporate ladder. Indeed, narcissism levels are typically higher for people in higher positions in organizations (e.g., Ahmetoglu et al., 2016; Brunell et al., 2008; Engelen et al., 2016; Zhu \& Chen, 2015).

This association between narcissism and higher career attainment is commonly explained in terms of a selection effect whereby individuals with narcissistic tendencies select themselves into higher level positions and/or are selected into these positions. Self-selection implies that people actively seek out roles that are consistent with their self-appraisals. For people with grandiose self-concepts -which is a hallmark characteristic of narcissism (Campbell et al., 2011; Paulhus \& Williams, 2002) - self-selection processes will operate in that these people will seek out work roles that offer leadership opportunities and positions that society perceives as 'highstatus' (Campbell \& Campbell, 2009). Moreover, narcissists typically have a stronger need for achievement and power ("getting ahead") than for close and intimate social relations ("getting along”) (Miller, Price, Gentile, Lynam, \& Campbell, 2012; Rhodewalt \& Morf, 1995; Rogoza, Wyszynska, Mackiewicz, \& Cieciuch, 2016). Accordingly, narcissists usually prefer situations and are more strongly motivated in situations in which there is a perceived opportunity for glory and status (Wallace \& Baumeister, 2002).

Besides self-selection, narcissists also have a greater chance of being selected into higher level positions. Many of narcissists' characteristics, such as being socially dominant, extraverted, and having high self-esteem, match the conception of the prototypical leader (Deluga, 1997; Ensari, Riggio, Christian, \& Carslaw, 2011; Judge, Bono, Ilies, \& Gerhardt, 2002). Experimental small group research showed that, during brief interactions, narcissists behave more dominant and expressive, which makes them being perceived as more assertive and leaderlike (Leckelt, Küfner, Nestler, \& Back, 2015). The employment interview is exactly such a short-term 
interaction wherein people with stronger narcissistic tendencies can display a range of selfpresentation behaviors and, as a result, tend to perform well (i.e., receive better evaluations; Paulhus, Westlake, Stryker, \& Harms, 2013). Moreover, it seems that narcissists are particularly advantaged when it comes to being promoted into top-level positions. Not only do people at the top of organizations (e.g., CEO's) demonstrate higher narcissism levels themselves, but research also found that CEO's tend to prefer people with similarly high narcissism levels when other upper-echelon positions in the organization (e.g., director positions) are filled (Zhu \& Chen, 2015).

Taken together, narcissistic people not only actively seek out higher level jobs, but the selection process can also take a passive form when more narcissistic people are perceived as a better fit for higher level jobs by organizational gatekeepers with selection or promotion authority.

\section{The Effect of Work on Personality Development}

Over the past decade, research has accumulated showing that personality not only predicts, but is also predicted by our life experiences, including those at work (Tasselli et al., 2018; Woods et al., 2013). The idea that personality continues to develop throughout adulthood in interaction with our environment is consistent with major developmental theories in psychology, including Baltes’ (1987) life span development perspective. More specifically, a core assumption of the life span perspective is that personality does not simply passively unfold as a consequence of the prewired maturational programs or the mechanistic reaction to environmental stimuli; instead, personality develops out of a constant and active process of the individual's transactions with changing internal (e.g., biological) and external influences (Baltes, Lindenberger, \& Staudinger, 2006). 
Within the personality development literature, the Neo-Socioanalytic model of personality (Roberts \& Nickel, 2017) is currently among the most widely used perspectives to further clarify such dynamic interactions between internal traits and external situations. More specifically, a basic tenet of this theory is that investing in age-graded social roles, such as school, work, and family, is one of the driving mechanisms of personality development (i.e., the social investment principle; Roberts \& Woods, 2006). Drawing on this broad theory, more specific frameworks such as the Attraction-Selection-Transformation-Manipulation (ASTMA) Model (Roberts, 2006) and more recently the Demands-Affordances TransActional (DATA) model (Woods et al., 2019) have also been developed to clarify the dynamic association between personality and role experiences, particularly at work. A common thread running through these frameworks is the idea that the association between personality and (work) role characteristics or experiences is bidirectional rather than unidirectional, with traits shaping our roles (i.e., manipulation) and role characteristics and/or experiences shaping traits (i.e., transformation).

In addition, we can turn to the Personality and Role Identity Structural Model (PRISM; Wood \& Roberts, 2006) to describe at a more micro-level the processes through which personality and work influence each other (e.g., Wille \& De Fruyt, 2014). The PRISM presents a hierarchy with multiple levels of varying breadth: (a) the general identity, representing how the person sees him/herself in general; (b) role identities, which represent perceptions of narrower, context-specific dispositions (e.g., "how I see myself in a professional context"); (c) aggregated role outcomes, such as general thoughts, feelings, and behavioral patterns within a role; and (d) single and concrete experiences occurring in a given role. In the PRISM, role identities are of particular importance because they might offer a way to understand how life experiences affect personality traits over time. Specifically, when an individual commits to a social role, his or her personality is expected to gradually shift to reflect the expectancies of that role. This happens 
because specific patterns of behaviors and feelings within these roles are rewarded (or punished) on the basis of role requirements and expectations, which in the long run gradually changes personality in response to these contingencies.

In the current work, we use the PRISM to explain how career attainment — as an outcome of one's professional functioning — may foster the development of narcissism over time. Specifically, drawing on the PRISM, we argue that repeated success (i.e., concrete role outcomes) may convince people with latent narcissistic tendencies that they are really better than others at work (i.e., role identity), an idea that, over time, can become solidified in their personality (or general identity).

This final step, i.e. the spillover from one's work role identity to one's general identity, involves both associative (implicit) and reflective (explicit) learning processes (Wrzus \& Roberts, 2017). For example, repeated attention to praise by significant others (e.g., colleagues at work) and the associated experience of intense positive affect following the praise, have been argued to form an implicit pathway for narcissistic qualities (Brummelman et al., 2015). This process can further be strengthened by external reinforcement, such as other's verbal or non-verbal reactions to narcissistic behaviors. In addition to association, also reflective processes maintain and strengthen personality by consciously thinking about one's past experiences, behavior, thoughts, and feelings (Wrzus \& Roberts, 2017). These explicit reflections can involve very short experiences, such as thinking about a specific ego-boosting experience at work, or longer, multiple experiences, such as the accumulation of professional accomplishment that led to a promotion decision.

\section{The Bidirectional Perspective on Narcissism and Career Attainment: Hypotheses}

Drawing on the mechanisms described above, we propose an integrative, bidirectional perspective on narcissism and career attainment (see Figure 1). The upper half of the model 
shows the widely acknowledged selection processes, active and passive, which explain the predictive effects from narcissism to higher career attainment. What is novel for this literature on narcissism, however, is that the proposed model also includes a reverse path, capturing the idea that higher career attainment also stimulates the development of narcissism over time (i.e., lower half of the model in Figure 1). This reverse path explains how objective indicators of career attainment can become assimilated in a role identity, which specifies how one sees him or herself at work based on concrete role experiences and aggregated role outcomes. Through a combination of associative and reflective mechanisms, this role experience information can slowly transmute up to the general disposition level. The assumption that a person's general identity, including one's level of narcissism, is formed of a combination of more context-specific identities is a fundamental developmental hypothesis (e.g., Gergen, 1991), suggesting that role identities show a particular mediating role between life experiences and personality change.

Combined, this bidirectional perspective incorporates a fundamental condition of human life course development which has been ignored in narcissism research to date, namely that the associations between individual traits and life conditions reflect two mutually supportive life course dynamics: Social selection and social influence (Roberts, Donnellan, \& Hill, 2012). Social selection refers to the processes through which the individual's personal characteristics shape his/her social conditions, whereas social influence (cf., 'socialization') refers to the processes through which contextual conditions shape the individual's characteristics. The combined effect of these two processes is that personality traits help shape an individual's life experiences, which in turn facilitate the development of personality traits across the life span, eventually resulting in a corresponsive mechanism (Caspi et al., 2005) or gain spiral. This means that the effect of life conditions on personality is to deepen or amplify the personal characteristics that are prospectively associated with those conditions in the first place. When applied to narcissism and 
career attainment, this perspective predicts that narcissistic tendencies facilitate upward mobility and, as a response to this success, people's narcissistic tendencies are further strengthened. This means that the bidirectional perspective on narcissism and career attainment proposes a positive feedback loop between narcissism and upward mobility over time. In line with the mechanisms described above, this translates into three hypotheses.

Our first hypothesis focusses on the end result of the proposed positive feedback loop, which is co-development (i.e., development in similar directions; Orth, Erol, Ledermann, \& Grob, 2018) between narcissism and upward mobility over time. This means that increases (decreases) in managerial level are expected to go hand in hand with increases (decreases) in narcissism over the same period of time. More formally, we hypothesize that:

Hypothesis 1: There is positively correlated change between narcissism and managerial level across the same period of time.

Correlated change is essential to life span perspectives because it expresses the fundamental idea that people develop in interaction with their environment (Hertzog \& Nesselroade, 2003). However, correlated change does not offer any insight into the nature of the time-sequential relations between variables over time, or how narcissism predicts subsequent upward mobility and vice versa. Therefore, the next two hypotheses zoom in on these respective selection and socialization effects, explicitly testing the nature of the bidirectional relation between narcissism and upward mobility. First, selection means that we expect narcissism to positively predict subsequent upward mobility, or more formally:

Hypothesis 2: There is a positive time-sequential effect from narcissism at Time $\mathrm{T}$ on subsequent change in managerial level at Time $\mathrm{T}+1$.

Finally, the bidirectional perspective also entails socialization effects, which means that upward mobility is expected to positively predict subsequent increases in narcissism, or more formally: 
Hypothesis 3: There is a positive time-sequential effect from career attainment at Time T on subsequent change in narcissism at Time $\mathrm{T}+1$.

\section{METHOD}

\section{Design and Participants}

Data came from a longitudinal project on personality and career unfolding in a Belgian college alumni sample (for extensive descriptions of this project see De Fruyt \& Mervielde, 1999; Wille et al., 2013). Three months prior to graduation (1994; wave 1), a large cohort of final year college students $(N=934)$, representing a wide range of study majors, enrolled in this research program and provided baseline personality information. Up till now, four follow-ups of this sample have been conducted: After 1 year on the labor market (1995; wave 2), after 15 years (2009; wave 3), after 16 years (2010; wave 4) and after 22 years (2016; wave 5).

Prior research used waves 1 to 4 from this dataset to investigate the long-term predictive validity of general (i.e. Big Five) personality traits with regard to individual career paths (Wille, Beyers, \& De Fruyt, 2012; Wille \& De Fruyt, 2014; Wille, De Fruyt, \& Feys, 2010) and career success (Vergauwe, Wille, Hofmans, \& De Fruyt, 2017; Wille, De Fruyt, \& Feys, 2013). Further, this panel was also used to investigate the long-term predictive validity of dark side personality tendencies assessed at the career start (wave 1) with regard to future career outcomes assessed 15 years later (wave 4; Wille et al., 2013).

The current study extends previous research by adding a new wave and thus by focusing on the temporal dynamics between narcissism and higher career attainment over a 22-year time frame. More specifically, this study is the first to use this panel to model changes in narcissism across time, and to investigate how these changes predict and are predicted by career development over time. To this end, we relied on data collected in 1994 (wave 1; further referred 
to as $T 1$ in the current study), 2009 (wave 3; further referred to as T2), and 2016 (wave 5; further referred to as T3). These waves were selected because they all included a measure of narcissistic personality. Participants' mean age was $22.59(S D=2.23), 37.33(S D=1.67)$, and 44.37 years $(S D=1.79)$ at $T 1, T 2$, and $T 3$ respectively.

The sample sizes across the three assessment waves vary according to the variables that are considered (see Table 1) and selectivity in dropout was examined in several steps. With regard to attrition between $T 1$ and $T 2$, continuers $(n=361)$ were compared to dropouts $(n=572)$ in terms of $T 1$ narcissism scores (note that at $T 1$ managerial level was zero for everyone). The result indicated no significant univariate difference in narcissism between both groups $(p=.099)$. With regard to attrition between $T 2$ and $T 3$, continuers and dropouts were compared on $T 2$ scores on narcissism as well as on $T 2$ managerial level. Again, continuers' $(\mathrm{n}=224)$ scores on $T 2$ narcissism were not significantly different from dropouts' $(n=142)$ scores $(p=.816)$. Similarly, continuers $(n=164)$ did not score significantly different from dropouts $(n=77)$ in terms of $T 2$ managerial level $(p=.258)$. Finally, we also ran Little's (1988) multivariate test using the SPSS Missing Value Analysis module (Howell, 2007). Missingness was completely at random (MCAR; $\chi^{2}=43.33, d f=51, p=.769$ ), which indicates that the probability of nonresponse (or dropout) in this sample is unrelated to any of the assessed study variables.

\section{Measures}

Narcissism $(T 1, T 2$, and T3). Our measurement of narcissism adhered to a model of subclinical personality pathology which operationalizes personality dysfunctioning in terms of the underlying traits. Specifically, the Personality Disorder (PD) additive count technique (Miller, Bagby, Pilkonis, Reynolds, \& Lynam, 2005) was used to generate Five-Factor Model (FFM)derived estimates of narcissism based on ratings from the NEO PI-R (Dutch version; Hoekstra, Ormel, \& De Fruyt, 1996). The NEO PI-R is a 240-item Likert-type self-report personality 
questionnaire measuring 30 narrow facets which are typically combined into five higher order domains (the Big Five). However, this facet-level information can also be used to assess disordered personality at a subclinical level, including narcissism. Specifically, the FFM PD count technique relied on expert-generated prototypes to identify a selected set of NEO PI-R facets which are at the heart of narcissistic PD (Miller, Reynolds, \& Pilkonis, 2004). As a result, the narcissistic count score is computed as a linear combination of 13 NEO PI-R facets, using the following formula:

$$
\begin{aligned}
\text { Narcissism }= & N 2+N 4(R)+E 1(R)+E 3+E 5+O 3(R)+O 4+A 1(R)+A 2(R)+A 3(R)+ \\
& A 4(R)+A 5(R)+A 6(R),
\end{aligned}
$$

whereby $(\mathrm{R})$ indicates that the facet must first be reverse scored before computing the count score. Table A1 in the appendix gives an overview of the various NEO PI-R facets included in the narcissism count score and how they are manifested.

In terms of the validation of this measure, several studies provided strong support for the convergent validity evidence of the narcissistic count score in relation to more direct measures of narcissistic symptomatology (Miller et al., 2005; Miller et al., 2008). The approach is also widely applied across various domains in psychology (e.g., Ahmetoglu et al., 2016; De Fruyt et al., 2009; Maples et al., 2010; Miller, Few, Lynam, \& MacKillop, 2015; Watts et al., 2013). Last but not least, this approach is instantiated in the Diagnostic and Statistical Manual of Mental Disorders (5 ${ }^{\text {th }}$ ed.; DSM-5; American Psychiatric Association [APA], 2013) as a core part of describing PDs, including the narcissistic PD in section III.

It is common in longitudinal research to test for measurement invariance (MI) of the assessed constructs across time. To the best of our knowledge, there is no specific procedure to conduct MI analyses in case of compound scales, such as the narcissistic compound included in this study. So, we performed a MI analysis for each of the 13 personality facet scales which are 
considered the building blocks of the compound. To this end, for each facet we first examined whether the same factor configuration held across time (i.e., configural invariance) by estimating a single confirmatory factor analysis model in which all model parameters not required for identification purposes were estimated freely at all time points. More specifically, apart from the factor variances (which were fixed to one) and the factor means (fixed to zero), all model parameters were freely estimated. Second, metric MI was tested by constraining the factor loadings to be equal across time. To this end, we tested a model in which the factor means were fixed to zero, the factor variance at T1 was fixed to one and the factor loadings were constrained to be equal across T1, T2 and T3. Finally, scalar MI was evaluated by also constraining the item intercepts to be equal across time. In this model, the factor mean at T1 was fixed to zero, the factor variance at T1 was fixed to one, and both the factor loadings and item intercepts were constrained to be equal across T1, T2 and T3. Each time after having placed additional constraints on the model, we tested change in model fit using $\triangle C F I$. As Meade, Johnson, and Braddy (2008) argue, when $\triangle C F I$ values exceed .002, this suggests that at least one of the constrained parameters is non-invariant (see also Nye, Bradburn, Olenick, Bialko, \& Drasgow, 2019). In case this happened, we explored potential causes of noninvariance using the modification indices. That is, the parameter constraint found to contribute most to model misfit was removed (i.e., the constraint with the largest modification index), and the model was subsequently re-estimated and re-evaluated. The results of this procedure are reported in Table A2 in the Appendix. For the bulk of facets, even the most constrained models still demonstrated decent model fit. So, it appears there is sufficient evidence in favor of our approach to use the narcissism items for making comparisons across time.

Managerial level (T2 and T3). We assessed self-report managerial level at $T 2$ and $T 3$ via five response categories: 1 = below management level, $2=$ lower management job, $3=$ middle 
management job, 4 = top management job in a small company (less than 250 employees $)$ and $5=$ top management job in a large company (more than 250 employees). This measure is in line with, for instance, Stroh et al.'s (1992) 4-point scale of managerial career success (i.e., 1 = nonmanagement/professional, $2=$ lower management, $3=$ middle management, and $4=$ upper management). For the current study, upper or top management was split into two subcategories to allow additional differentiation at the high end of the distribution. We specifically differentiated between top management in small versus large companies based on the logic that the latter tend to require a taller hierarchy, meaning that the attainment of top levels is more challenging and/or requires more upward mobility (as compared to smaller organizations).

\section{Analyses}

To test the dynamic interrelationships between narcissism and managerial level, we modeled the longitudinal data using the extended multivariate Latent Difference Score (LDS) model of Grimm, An, McArdle, Zonderman, and Resnick (2012). This model is an extension of the traditional multivariate LDS model in that it not only models level-on-change relationships, but also tests how previous changes relate to subsequent changes. That is, whereas the traditional multivariate LDS model tests only whether inter-individual differences (i.e., level) in one variable predict intra-individual differences (i.e., change) in another variable, the extended multivariate LDS model additionally tests whether intra-individual differences (i.e., change) in one variable trigger intra-individual differences (i.e., change) in the other variable. This is of critical importance for this study because the idea that narcissistic tendencies facilitate upward mobility and that these success experiences in turn further strengthen people's narcissistic tendencies implies testing whether changes in narcissism predict subsequent changes in career success and vice versa. 
Figure 2 displays all paths of the tested model and Table 2 gives an overview of all parameters that are particularly relevant for the current study. Note that several paths in Figure 2 are unlabeled (e.g., between $\mathrm{N}_{\mathrm{T} 1}$ and $\mathrm{N}_{\mathrm{T} 2}$ ) which indicates that these are fixed equal to 1; other paths have the same label (i.e., $\Upsilon_{N}, \beta_{N}$ ) which means that they are constrained to be equal over time (see also Grimm et al., 2012). The extended multivariate LDS model consists of two coupled univariate LDS models: one for narcissism (shown in the upper half of the figure) and one for managerial level (shown in the lower half of Figure 2) ${ }^{1}$. In both univariate models, the observed score at time $T$-represented by the squares in Figure 2 - is separated into a true score at time $T$ (i.e., the ellipses in Figure 2) and a unique score at time $T$ (i.e., the $\varepsilon$ terms in Figure 2). To create the latent difference scores, the true scores are specified to follow a fixed-unit autoregressive process according to which the true score at time $T+1$ consists of the true score at time $T$ plus change in the true score from time $T$ to $T+1$ (i.e., the $\Delta$ terms in Figure 2).

As Figure 2 shows, there are no data for managerial level at time T1: At time T1, all participants were still students. Thus, managerial level was 0 for all participants at the start of the study. This peculiarity in the data has a number of important implications. First, although we have an intercept parameter for narcissism (capturing inter-individual differences in narcissism at T1), the intercept parameter for managerial level was omitted from the model because everyone started at zero. Second, as managerial level was 0 at $T 1$, the true score of managerial level at $T 2$ captures both the level of managerial level at $T 2$ and change in managerial level between $T 1$ and

\footnotetext{
${ }^{1}$ Based on a reviewer's suggestion, we also tested this model including participants' study major as a control variable. In this model, study major serves as a predictor variable for the intercept and slope of narcissism and the slope of managerial level. However, the obtained results were completely in line with what we currently report (i.e., without major as a control). The results from the model including study major can be downloaded from https://osf.io/htcmj/?view_only=9f165b9b82304f1ca86a2fb7753030e3.
} 
$T 2$. Hence, it is used both in the autoregressive process of $T 3$ and for testing the change-tochange relationship between managerial level and narcissism.

The temporal dynamics of narcissism and managerial level are captured in several ways (see also Table 2). First, $S_{N}$ and $S_{M L}$ represent the linear slopes of narcissism and managerial level respectively, and therefore capture constant, linear change across the entire time period. In addition, the model contains two parameters which grasp the time-sequential dynamics of narcissism and managerial level, or how both constructs evolve (separately) from one time point to the other (Kim-Spoon \& Grimm, 2016). Specifically, the $\beta$ parameters in Figure 2 capture proportional change, meaning that they tell us to what extent change in narcissism at time $T+1$ depends on the level of narcissism at time $T$. Note that, for the current analyses, the $\beta$ parameters (i.e., T1 $\rightarrow \mathrm{T} 2$ and $\mathrm{T} 2 \rightarrow \mathrm{T} 3$ ) were constrained to be equal over time. Finally, the $\phi$ parameters capture dual change (or 'change-to-change'), meaning that they reveal whether change in narcissism (managerial level) from time $T$ to time $T+1$ depends on change in narcissism (managerial level) from time $T-1$ to time $T$.

Apart from capturing the temporal dynamics within each univariate model, the dynamic interrelations between the two univariate LDS models are modeled via a set of coupling parameters. First, two coupling parameters capture the interrelations between narcissism and managerial level across the entire time interval. More specifically, the latent slope factors of narcissism and managerial level are correlated (i.e., $\rho_{S N, S M L}$ ), which allows testing whether changes in both variables across the entire time interval are related (i.e., co-development; Hypothesis 1). In addition, the initial level (intercept) of narcissism and slope of managerial level are correlated (i.e., $\rho_{I N, S M L}$ ), which offers a first test of the idea that narcissism predicts increases in managerial level (i.e., selection; Hypothesis 2) across the entire time interval. 
Second, three coupling parameters capture time-sequential interrelations between narcissism and managerial level, or how both variables influence each other from one time interval to the other. Estimating the effects of initial narcissism on subsequent change in managerial level (i.e., proportional change; $\Upsilon_{N}$ ) and the effect of change in narcissism on subsequent change in managerial level (i.e., dual change; $\zeta_{N}$ ) represent two additional tests of the proposed selection process (i.e., Hypothesis 2). Similar as for the $\beta_{N}$ parameters, the $\gamma_{N}$ parameters were constrained to be equal over time. Finally, estimating the effect of managerial level at $\mathrm{T} 2$ on subsequent change in narcissism (i.e., $\zeta_{M L}$ ) allows testing whether upward mobility has an effect on later growth in narcissism (i.e., socialization; Hypothesis 3). Note again that, because there was no data about managerial level at $\mathrm{T} 1$, this last effect can represent dual change as well as proportional change.

The model was tested using Bayesian estimation in Mplus version 7.31 (Muthén \& Muthén, 2012). Although Bayesian analysis has only recently gained attention in the management literature (Zyphur \& Oswald, 2013), it has some important advantages over traditional inferential methods (Bidee et al., 2017). Two key advantages are that Bayesian estimation flexibly deals with data that violate standard analysis assumptions and that it allows testing models that are hard to fit (for a detailed discussion of Bayesian analysis see Kruschke, Aguinis, \& Joo, 2012). Due to the non-normality of the managerial level scores and the high complexity of our model, Bayesian estimation seemed particularly well suited. In contrast to the traditional - frequentist — approach, Bayesian analysis does not yield $p$-values or confidence intervals. Instead, it produces per parameter a probability distribution of the parameter given the data by combining prior parameter distributions with the data using Markov Chain Monte Carlo algorithms (Kruschke et al., 2012; Zyphur \& Oswald, 2015). Based on these posterior distributions, credibility intervals are constructed, referring to the likelihood that the interval 
covers the true parameter value, based on the observed data (Yuan \& MacKinnon, 2009). For example, a $95 \%$ credibility interval of $[1.00,2.00]$ means that there is a $95 \%$ chance that the true parameter value ranges between 1.00 and 2.00. As Bayesian analysis combines prior parameter distributions with the data to iteratively approximate the posterior parameter distributions, one needs to specify the prior distributions before the analysis. In this paper, we used the default, uninformative Mplus priors.

It is important to note, finally, that all reported parameters estimated in this modeling framework represent unstandardized coefficients. We therefore caution against making any inferences with regard to the strength of the reported effects.

\section{RESULTS}

\section{Descriptive Analyses}

As a first step, we tested the relationships between all observed study variables. As can be seen in Table 1, there were moderate positive relationships between narcissism at $T 1, T 2$, and $T 3$ and between managerial level at $T 2$ and $T 3$. Narcissism and managerial level were also positively correlated, suggesting that people with higher levels of narcissism hold higher managerial levels, and that this relationship held across waves.

\section{Latent Changes In Narcissism And Managerial Level}

In the next step, we modeled latent changes in narcissism and managerial level and their connections over time (see Table 2). Results from the upper half of the model show that, on average, participants demonstrated no significant linear growth in narcissism over the 22-year interval $\left(S_{N}=.09 ; 95 \%\right.$ credibility interval $\left.=[-.04, .21]\right)$. Importantly, the variance associated with this linear slope reveals that this should not be interpreted as a complete absence of slowpaced change in narcissism, but rather as the result of statistically significant between-person differences in the way individuals' narcissism levels evolved over time $\left(\operatorname{Var}\left(S_{N}\right)=.03 ; 95 \%\right.$ 
credibility interval $=[.02, .04])$. Individual slope estimates varied in this sample from -.61 to .27 , illustrating how some people showed decreases and others showed increases, and these opposite trajectories cancelled each other out at the mean level. Moreover, the intercept of narcissism was negatively related to the slope, meaning that people who have higher initial levels of narcissism show less increase or even a decrease in narcissism over the 22 -year period $\left(\rho_{I N, S N}=-.45 ; 95 \%\right.$ credibility interval $=[-.56,-.32])$. Turning to the time-sequential changes, there was little support for proportional change, meaning that change in narcissism between Times $T$ and $T+1$ did not depend on the level of narcissism at Time $T\left(\beta_{N}=-.04 ; 95 \%\right.$ credibility interval $\left.=[-.08, .01]\right)$. Instead, we did find support for dual change relationships, revealing that change in narcissism between $T 1$ and $T 2$ negatively predicted change in narcissism between $T 2$ and $T 3\left(\phi_{N}=-.76 ; 95 \%\right.$ credibility interval $=[-.90,-.61])$.

With respect to upward mobility, on average, participants' managerial levels increased $\left(S_{M L}=.82 ; 95 \%\right.$ credibility interval $\left.=[.69, .96]\right)$ although there are significant between-person differences in this linear trend $\left(\operatorname{Var}\left(S_{M L}\right)=.62 ; 95 \%\right.$ credibility interval $\left.=[.44, .85]\right)$. Regarding the time-sequential changes, managerial level at $T 2$ negatively predicted change in managerial level between $T 2$ and $T 3\left(\phi_{N}=-.53 ; 95 \%\right.$ credibility interval $\left.=[-.68,-.34]\right)$. As managerial level at $T 2$ captured both managerial level at $T 2$ and change in managerial level between $T 1$ and $T 2$, this finding suggests that people who are already at a higher level increase less (i.e., proportional change), that people who increased more in managerial level show less upward mobility in the next period (i.e., dual change), or that a combination of proportional change and dual change is at play.

\section{Associations Between Narcissism And Managerial Level Over Time}

Finally, Table 2 also presents the results for the coupling parameters linking narcissism to managerial level over time, which allows us to test the central elements of the proposed 
bidirectional perspective on narcissism and career attainment. First, consistent with our expectations (Hypothesis 1), results showed a positive correlation between the slopes of narcissism and managerial level, implying that greater increases in narcissism over the entire 22year interval go together with greater increases in managerial level across the same period of time $\left(\rho_{S N, S M L}=.35 ; 95 \%\right.$ credibility interval $\left.=[.19, .50]\right)$.

Second, two model parameters also provided support for Hypothesis 2, which predicted that narcissism positively predicts upward mobility. More specifically, the intercept of narcissism was positively related to the slope of managerial level, meaning that higher initial levels of narcissism at career start predict stronger growth in managerial level over the entire 22-year interval $\left(\rho_{I N, S M L}=.17 ; 95 \%\right.$ credibility interval $\left.=[.05, .29]\right)$. In addition, time-sequential paths showed that there is a positive effect from narcissism at Time $\mathrm{T}$ on subsequent change in managerial level at Time $\mathrm{T}+1$ (i.e., proportional change; $\Upsilon_{N}=.03 ; 95 \%$ credibility interval $=[.01$, .09]). However, this time-sequential effect was not significant when change in narcissism was used to predict subsequent change in managerial level (i.e., dual change; $\xi_{N}=-.58 ; 95 \%$ credibility interval $=[-.94, .11])$. This indicates that levels of narcissism, not change in narcissism, predict future upward mobility.

Finally, in contrast to our expectation (Hypothesis 3), the effect of (change in) managerial level on subsequent change in narcissism was significant but negative $\left(\xi_{M L}=-.04 ; 95 \%\right.$ credibility interval $=[-.06,-.02])$. Once again, as managerial level at $T 2$ captures both the level at $T 2$ and change in managerial level between $T 1$ and $T 2$, this finding implies that either the managerial level, or the change in managerial level, or a combination thereof negatively predicts subsequent change in narcissism.

\section{DISCUSSION}


The presence of narcissistic features in people in the highest echelons of organizations has become a topic of intense public debate and has also caught a lot of scholarly attention. What characterizes this stream of research is that, until now, it relied on a purely unidirectional perspective in which narcissism was considered the (stable) predictor, whereas career attainment served as the outcome which develops over time. Although it has often been suggested that the attainment of higher-level positions might also increase individual narcissism, until now “acquired situational narcissism" (Campbell et al., 2011, p. 273) has not yet been tested longitudinally. This is problematic in light of the growing evidence for plasticity in people's personality traits, and more specifically in view of the influence of work-related experiences on patterns of personality development (e.g., Tasselli et al., 2018; Woods, Lievens, et al., 2013; Woods, Wille, et al., 2019). Therefore, the current paper sought to investigate the dynamic and reciprocal relationships between narcissism and upward transitions on the corporate ladder. Hence, we responded to recent calls in management (e.g., Grijalva \& Harms, 2014; Tasselli et al., 2018) and personality (e.g., Grosz et al., 2019) literatures to investigate the developmental paths of this critical domain of personality functioning.

We first introduced an alternative theoretical framework that connects two mutually supportive life course dynamics, i.e., social selection and social influence or socialization, whereas previous research on narcissism and career attainment considered only half of the story by focusing exclusively on selection effects. Relying on this perspective, the current study extends the existing literature on narcissism and vertical mobility in three ways. First, it highlights that adult narcissism is not fixed as plaster, but that there is room for development as people grow older and give direction to their organizational careers. An important finding in this regard is that there was no clear pattern of normative growth or loss in narcissism across the entire 22-year interval. For instance, based on social investment theory (Roberts \& Wood, 2006), 
one could argue for an average decrease in narcissism because the developmental tasks accompanying social investment run contrary to the model mind sets of narcissists. More specifically, being hostile to the interests of others, which is a key element of narcissism, would preclude making deep and long-lasting connections with other people, which are necessary to succeed in the interpersonal roles of adulthood (Roberts et al., 2010). The current findings underscore that long-term change in narcissism exists, but also show that the direction and magnitude of this change vary significantly between persons. Subsets of individuals are increasing and others are decreasing and thus offsetting each other's change, resulting in no mean-level change overall (Roberts, Walton, \& Viechtbauer, 2006). The assumption hereby is that at least part of this interindividual variation in intraindividual change can be related to differences in the types of environments to which people are exposed (Caspi \& Roberts, 2001).

Delving into these environmental experiences, a second contribution is that our findings provide support for long-term positive co-development of narcissism and career growth over time. This form of correlated change (e.g., Allemand, Zimprich, \& Martin, 2008; Wille et al., 2014) provides evidence of personality and social roles enhancing one another over time, which is a cornerstone of neo-socioanalytic approaches to personality (Roberts \& Nickel, 2017). The current study is one of the first to apply this perspective to dark personality, in particular narcissism and how it relates to career advancement over time. Higher managerial positions are indeed a useful social platform for obtaining the narcissistic goals of self-enhancement, via, for instance, social status, material goods, admiration, and social power. These positions, as argued by Campbell and Campbell (2009), rather reinforce having power over others (agentic concerns) than forming close, warm relationships with others (communal concerns); a combination of environmental factors that closely matches narcissists' natural preferences. 
As a third key contribution, the present study delved deeper into the dynamic interaction between narcissism and upward mobility through means of time-sequential analyses. There was clear support for the idea that narcissism fosters individual career advancement over time, a process we explained as selection effects in the proposed bidirectional perspective. In addition, the present study was the first to demonstrate that there is also a reverse effect, from career attainment to subsequent change in narcissism, although this effect was in the opposite direction compared to what was expected. More specifically, people with steep career growth during the first stage of the career had smaller growth in narcissism during the next stage, which seems to indicate that the longitudinal recursive relationship between these variables is discontinuous rather than a clean gain spiral (Kim-Spoon \& Grimm, 2016). In other words, there are boundaries to the extent to which narcissism and career growth enhance each other over time; a finding which can be linked to the contextual reinforcement model of narcissism (Campbell \& Campbell, 2009). According to this model, narcissism is beneficial in the "emerging zone", which includes new leadership positions and leadership in chaotic situations. In contrast, narcissism is harmful in the "enduring zone", which includes long-held leadership positions and leadership in stable situations.

Although a certain level of narcissism at the start of one's career seems to facilitate upward mobility, once these higher-level roles are obtained, there is less pressure for continuous increases in narcissism. Indeed, there seems to be an optimal level of narcissism in relation to managerial effectiveness (Grijalva et al., 2015), and the co-development of narcissism and career growth may -in part- be regulated by this principle. Specifically, as extremely high levels of narcissism hinder rather than facilitate effective functioning in these roles, a phase of stabilization rather than a continued increase of narcissism seems beneficial once individuals have reached a certain echelon in the hierarchy. 
With regard to practical implications, the finding that narcissism continues to develop throughout one's career is crucial information for organizations given the many undesirable outcomes that are associated with more elevated levels of this trait. In particular, it highlights that single-shot assessment of narcissism might not be indicative of a person's trait standing after a certain period of time, particularly following the experience of upward transitions. In addition to screening for narcissism when individuals are hired (e.g., Engelen et al., 2016), organizations might therefore also benefit from monitoring narcissistic tendencies over time to keep track of people who start displaying or developing feelings of inflated self-worth.

\section{Strengths, Limitations and Future Research Directions}

The current study is the first to investigate how narcissism and career attainment interrelate over time. Changes in narcissism were tracked across more than two decades, covering the stages in which people's careers are established and consolidated. Furthermore, the availability of three measurement points allowed exploring the reciprocal nature of the codevelopment between narcissism and career attainment, thereby separating within-individual change trajectories from between-person differences. This is consistent with the conceptual buildup for the study which described how individuals change over time from a developmental perspective, and how understanding the trajectory of individual-level personality sheds new light on the association between narcissism and career attainment.

That said, three limitations of this study should be acknowledged. First, the timesequential analyses looking at how narcissism predicted subsequent change in managerial level (and vice versa) were limited in the current study because there were only three measurement points available. This means that the entire 22-year period could only be divided into two rather long time intervals with little insight into the developmental processes that unfolded within these two periods (and how they affected each other). Clearly, increasing the number of measurement 
points would enable more detailed time-sequential analyses which will offer a more fine-grained picture of how narcissism and career attainment continuously influence each other.

Second, future work might address the mediators and moderators of the dynamic association between narcissism and career attainment. Our conceptual model proposed that role identity mediates the effect of higher attainment on change in narcissism, but more research is needed on the specific types of associative and reflective learning processes that foster the spillover from one's work role identity to one's general identity (Wrzus \& Roberts, 2017). For instance, the link between career attainment and narcissism might be explained by perceived rewards and status that accompany higher level jobs, or by different task-related demands that activate specific personality states (e.g., Woods et al., 2019). To further disentangle these processes, future research can, for instance, also measure the concrete work experiences that are associated with taking up managerial responsibilities, and how these influence people's mindset. Theory on personality development at work specifies that the repeated activation of certain traits in response to particular work demands is key to understanding long-term personality change (Roberts, 2006; Woods et al., 2019). Although prior research has begun to investigate how personality states can fluctuate at work (e.g., Judge, Simon, Hurst, \& Kelley, 2014; Debusscher, Hofmans, \& De Fruyt, 2016a, 2016b), little is known about how managerial activities in particular influence momentary fluctuations in narcissistic tendencies.

Next to these mediating mechanisms, future work can refine our proposed bidirectional perspective on narcissism and career attainment by describing and testing moderators of the socialization process, particularly the association between work role identity and general identity. For instance, the degree to which a particular life role (e.g., work) is central to a person's identity might play a role in studying reciprocal effects between these role experiences and identity 
development. Only in case of high work centrality, concrete experiences and outcomes associated with this life domain might have an effect on higher level identity development.

A final limitation relates to the measure of narcissistic personality that was used in the current study. Specifically, by using the FFM narcissistic count score, our analyses treated narcissism as a unitary construct, which is common in applied psychology. However, more recent work in personality and social psychology makes a distinction between more agentic/extraverted and more antagonistic/disagreeable aspects of grandiose narcissism (e.g., Back, 2018; Back et al., 2013; also see Crowe, Lynam, Campbell, \& Miller, 2019; Krizan \& Herlache, 2018; Wright \& Edershile, 2018). It remains to be examined to which extent these facets of narcissism also have distinct career-related outcomes and different developmental determinants.

\section{Conclusion}

Despite recent awareness that personality continues to develop throughout the entire lifespan, prior research treated narcissism as a stable characteristic when establishing its correlates in the work setting. Addressing this constraint, this paper presented and tested a bidirectional perspective on narcissism and career attainment in which both dynamic constructs are proposed to co-develop and influence each other over time. Partly confirming our expectations, climbing the career ladder seems to go hand in hand with increases in narcissism in the long term. However, the precise nature of the reciprocal relationship between both variables remains somewhat unclear, particularly the negative time-sequential effect from higher attainment to subsequent change in narcissism. We hope that future research further tests and refines this bidirectional perspective by adopting more intensive longitudinal designs, including additional mediating and moderating variables, and considering more differentiated measures of narcissistic personality. 


\section{References}

Ackerman, R. A., Witt, E. A., Donnellan, M. B., Trzesniewski, K. H., Robins, R. W., \& Kashy, D. A. (2011). What does the narcissistic personality inventory really measure? Assessment, 18, 67-87.

Ahmetoglu, G., Dobbs, S., Furnham, A., Crump, J., Chamorro-Premuzic, T., \& Bakhshalian, E. (2016). Dark side of personality, intelligence, creativity, and managerial level. Journal of Managerial Psychology, 31, 391-404.

Allemand, M., Zimprich, D., \& Martin, M. (2008). Long-term correlated change in personality traits in old age. Psychology and Aging, 23, 545-557.

American Psychiatric Association. (2013). Diagnostic and statistical manual of mental disorders (5th ed.). Washington, DC: Author.

Back, M. D. (2018). The Narcissistic Admiration and Rivalry Concept. In A. D. Hermann, A. Brunell, \& J. Foster (Eds.), The Handbook of trait narcissism: Key advances, research methods, and controversies (pp. 57-67). New York, NY: Springer.

Back, M. D., Küfner, A. C. P., Dufner, M., Gerlach, T. M., Rauthmann, J. F., \& Denissen, J. J. A. (2013). Narcissistic admiration and rivalry: Disentangling the bright and dark sides of narcissism. Journal of Personality and Social Psychology, 105, 1013-1037.

Baltes, M. M. (1987). Erfolgreiches altern als ausdruck von verhaltenskompetenz und umweltqualität. In C. Niemitz (Ed.), Der mensch im zusammenspiel von anlage und umwelt (pp. 353-377). Frankfurt-am-Main, Germany: Suhrkamp.

Baltes, P. B., Lindenberger, U., \& Staudinger, U. M. (2006). Life Span Theory in Developmental Psychology. In R. M. Lerner \& W. Damon (Eds.), Handbook of child psychology: Theoretical models of human development (pp. 569-664). Hoboken, NJ: John Wiley \& Sons Inc. 
Bidee, J., Vantilborgh, T., Pepermans, R., Willems, J., Jegers, M., \& Hofmans, J. (2017). Daily motivation of volunteers in healthcare organizations: relating team inclusion and intrinsic motivation using self-determination theory. European Journal of Work and Organizational Psychology, 26, 325-336.

Brummelman, E., Thomaes, S., Nelemans, S. A., Orobio de Castro, B., Overbeek, G., \& Bushman, B. J. (2015). Origins of narcissism in children. Proceedings of the National Academy of Sciences, 112, 3659-3662.

Brunell A. B, Gentry, W. A., Campbell, W. K. ,Hoffman B. J., Kuhnert, K. W., \& DeMarree, K. G. (2008). Leader emergence: the case of the narcissistic leader. Personality and Social Psychology Bulletin, 34, 1663-76

Buyl, T., Boone, C., \& Wade, J. B. (2019). CEO narcissism, risk taking, and resilience: An empirical analysis in U.S. commercial banks. Journal of Management, 45, 1372-1400.

Campbell, W. K., \& Campbell, S. M. (2009). On the self-regulatory dynamics created by the peculiar benefits and costs of narcissism: A contextual reinforcement model and examination of leadership. Self and Identity, 8, 214-232.

Campbell, W. K., Hoffman, B. J., Campbell, S. M., \& Marchisio, G. (2011). Narcissism in organizational contexts. Human Resource Management Review, 21, 268-284.

Carlson, K. S., \& Gjerde, P. F. (2009). Preschool personality antecedents of narcissism in adolescence and young adulthood: A 20-year longitudinal study. Journal of Research in Personality, 43, 570-578.

Caspi, A., \& Roberts, B. W. (2001). Personality development across the life course: The argument for change and continuity. Psychological Inquiry, 12, 49-66.

Caspi, A., Roberts, B. W., \& Shiner, R. L. (2005). Personality development: Stability and change. Annual Review of Psychology, 56, 453-484. 
Chatterjee, A., \& Hambrick, D. C. (2007). It's all about me: Narcissistic chief executive officers and their effects on company strategy and performance. Administrative Science Quarterly, $52,351-386$.

Chatterjee, A., \& Hambrick, D. C. (2011). Executive personality, capability cues, and risk taking: How narcissistic CEOs react to their successes and stumbles. Administrative Science Quarterly, 56, 202-237.

Costa, P. T., Jr., \& McCrae, R. R. (1994). Set like plaster: Evidence for the stability of adult personality. In T. F. Heatherton \& J. L. Weinberger (Eds.), Can personality change? (pp. 21-40). Washington, DC: American Psychological Association.

Crowe, M. L., Lynam, D. R., Campbell, W. K., \& Miller, J. D. (2019). Exploring the structure of narcissism: Toward an integrated solution. Journal of Personality. Advance online publication. https://doi.org/10.1111/jopy.12464

Debusscher, J., Hofmans, J., \& De Fruyt, F. (2016a). From state neuroticism to momentary task performance: A person x situation approach. European Journal of Work and Organizational Psychology, 25, 89-104.

Debusscher, J., Hofmans, J., \& De Fruyt, F. (2016b). Do personality states predict momentary task performance? The moderating role of personality variability. Journal of Occupational and Organizational Psychology, 89, 330-351.

De Fruyt, F., De Clercq, B. J., Miller, J., Rolland, J. P., Jung, S. C., Taris, R., . . Van Hiel, A. (2009). Assessing personality at risk in personnel selection and development. European Journal of Personality, 23, 51-69.

De Fruyt, F., \& Mervielde, I. (1999). RIASEC types and Big Five traits as predictors of employment status and nature of employment. Personnel Psychology, 52, 701-727. 
Deluga, R. J. (1997). Relationship among American presidential charismatic leadership, narcissism, and rated performance. Leadership Quarterly, 8, 49-65.

Engelen, A., Neumann, C., \& Schmidt, S. (2016). Should entrepreneurially oriented firms have narcissistic CEOs? Journal of Management, 42, 698-721.

Ensari, N., Riggio, R. E., Christian, J., \& Carslaw, G. (2011). Who emerges as a leader? Metaanalyses of individual differences as predictors of leadership emergence. Personality and Individual Differences, 51, 532-536.

Foster, J. D., Campbell, W. K., \& Twenge, J. M. (2003). Individual differences in narcissism: Inflated self-views across the lifespan and around the world. Journal of Research in Personality, 37, 469-486.

Gergen, K. J. (1991). The saturated self: Dilemmas of identity in contemporary life. New York: Basic Books.

Grijalva, E., \& Harms, P. D. (2014). Narcissism: An integrative synthesis and dominance complementarity model. Academy of Management Perspectives, 28, 108-127.

Grijalva, E., Harms, P. D., Newman, D. A., Gaddis, B. H., \& Fraley, R. C. (2015). Narcissism and leadership: A meta-analytic review of linear and nonlinear relationships. Personnel Psychology, 68, 1-47.

Grimm, K. J., An, Y., McArdle, J. J., Zonderman, A. B., \& Resnick, S. M. (2012). Recent changes leading to subsequent changes: Extensions of multivariate latent difference score models. Structural Equation Modeling-a Multidisciplinary Journal, 19, 268-292.

Grosz, M. P., Göllner, R., Rose, N., Spengler, M., Trautwein, U., Rauthmann, J. F., . . Roberts, B. W. (2019). The development of narcissistic admiration and machiavellianism in early adulthood. Journal of Personality and Social Psychology, 116, 467-482. 
Harms, P. D., Spain, S. M., \& Hannah, S. T. (2011). Leader development and the dark side of personality. Leadership Quarterly, 22, 495-509.

Hertzog, C., \& Nesselroade, J. R. (2003). Assessing psychological change in adulthood: An overview of methodological issues. Psychology and Aging, 18, 639-657.

Hoekstra, H. A., Ormel, J., \& De Fruyt, F. (1996). NEO Persoonlijkheidsvragenlijsten NEO-PI-R en NEO-FFI. Handleiding [NEO Personality Inventories: NEO-PI-R and NEO-FFI manual.]. Lisse: Swets \& Zeitlinger.

Hogan, R., Curphy, G. J., \& Hogan, J. (1994). What we know about leadership: Effectiveness and personality. American Psychologist, 49, 493-504.

Howell, D. C. (2007). The treatment of missing data. In W. Outhwaite \& S. P. Turner (Eds.), The SAGE handbook of social science methodology (pp. 208-224). Thousand Oaks, California: SAGE Publications Inc.

Judge, T. A., Bono, J. E., Ilies, R., \& Gerhardt, M. W. (2002). Personality and leadership: A qualitative and quantitative review. Journal of Applied Psychology, 87, 765-780.

Judge, T. A., Simon, L. S., Hurst, C., \& Kelley, K. (2014). What I experienced yesterday is who I am today: Relationship of work motivations and behaviors to within-individual variation in the five-factor model of personality. Journal of Applied Psychology, 99, 199-221.

Kim-Spoon, J., \& Grimm, K. J. (2016). Latent growth modeling and developmental psychopathology. In D. Cichetti (Ed.), Developmental psychopathology (3rd ed.: 9861041). Hoboken, NJ: Wiley.

Krizan, Z., \& Herlache, A. D. (2018). The Narcissism Spectrum Model: A synthetic view of narcissistic personality. Personality and Social Psychology Review, 22, 3-31.

Kruschke, J. K., Aguinis, H., \& Joo, H. (2012). The time has come: Bayesian methods for data analysis in the organizational sciences. Organizational Research Methods, 15, 722-752. 
Leckelt, M., Küfner, A. C. P., Nestler, S., \& Back, M. D. (2015). Behavioral processes underlying the decline of narcissists' popularity over time. Journal of Personality and Social Psychology, 109, 856-871.

Little, R. J. A. (1988). Missing data in large surveys. Journal of Business and Economic Statistics, 6, 287-301.

Maples, J. L., Miller, J. D., Wilson, L. F., Seibert, L. A., Few, L. R., \& Zeichner, A. (2010). Narcissistic personality disorder and self-esteem: An examination of differential relations with self-report and laboratory-based aggression. Journal of Research in Personality, 44, 559-563.

Martin, S. R., Cote, S., \& Woodruff, T. (2016). Echoes of our upbringing: How growing up wealthy or poor relates to narcissism, leader behavior, and leader effectiveness. Academy of Management Journal, 59, 2157-2177.

Meade, A. W., Johnson, E. C., \& Braddy, P. W. (2008). Power and sensitivity of alternative fit indices in tests of measurement invariance. Journal of applied psychology, 93, 568.

Miller, J. D., Bagby, R. M., Pilkonis, P. A., Reynolds, S. K., \& Lynam, D. R. (2005). A simplified technique for scoring DSM-IV personality disorders with the five-factor model. Assessment, 12, 404-415.

Miller, J. D., Few, L. R., Lynam, D. R., \& MacKillop, J. (2015). Pathological personality traits can capture DSM-IV personality disorder types. Personality Disorders: Theory, Research, and Treatment, 6, 32-40.

Miller, J. D., Lynam, D. R., Rolland, J. P., De Fruyt, F., Reynolds, S. K., Pham-Scottez, A., . . Bagby, R. M. (2008). Scoring the DSM-IV personality disorders using the Five-Factor Model: Development and validation of normative scores for North American, French, and Dutch-Flemish samples. Journal of Personality Disorders, 22, 433-450. 
Miller, J. D., Price, J., Gentile, B., Lynam, D. R., \& Campbell, W. K. (2012). Grandiose and vulnerable narcissism from the perspective of the interpersonal circumplex. Personality and Individual Differences, 53, 507-512.

Miller, J. D., Reynolds, S. K., \& Pilkonis, P. A. (2004). The validity of the five-factor model prototypes for personality disorders in two clinical samples. Psychological Assessment, $16,310-322$.

Morf, C. C., \& Rhodewalt, F. (2001). Unraveling the paradoxes of narcissism: A dynamic selfregulatory processing model. Psychological Inquiry, 12, 177-196.

Muthén, L. K., \& Muthén, B. O. (2012). Mplus user's guide. Los Angeles, CA: Muthén \& Muthén.

Nye, C. D., Bradburn, J., Olenick, J., Bialko, C., \& Drasgow, F. (2019). How big are my effects? Examining the magnitude of effect sizes in studies of measurement equivalence. Organizational Research Methods, 22, 678-709.

Orth, U., Erol, R. Y., Ledermann, T., \& Grob, A. (2018). Codevelopment of Well-Being and Self-Esteem in Romantic Partners: Disentangling the Effects of Mutual Influence and Shared Environment. Developmental Psychology, 54, 151-166.

Orth, U., \& Luciano, E. C. (2015). Self-esteem, narcissism, and stressful life events: Testing for selection and socialization. Journal of Personality and Social Psychology, 109, 707-721.

O'Reilly, C.A., Doerr, B., \& Chatman, J. A. (2018). "See You in Court”: How CEO narcissism increases firms' vulnerability to lawsuits. The Leadership Quarterly, 29, 365-378.

Paulhus, D. L., Westlake, B. G., Calvez, S. S., \& Harms, P. D. (2013). Self-presentation style in job interviews: the role of personality and culture. Journal of Applied Social Psychology, 43, 2042-2059. 
Paulhus, D. L., \& Williams, K. M. (2002). The Dark Triad of personality: Narcissism, Machiavellianism, and psychopathy. Journal of Research in Personality, 36, 556-563.

Rhodewalt, F., \& Morf, C. C. (1995). Self and interpersonal correlates of the Narcissistic Personality Inventory: A review and new findings. Journal of Research in Personality, $29,1-23$.

Roberts, B. W. (2006). Personality development and organizational behavior. Research in Organizational Behavior, 27, 1-40.

Roberts, B. W., \& Caspi, A. (2003). The cumulative continuity model of personality development: Striking a balance between continuity and change in personality traits across the life course. In R. M. Staudinger \& U. Lindenberger (Eds.), Understanding human development: Lifespan psychology in exchange with other disciplines (pp. 183214). Dordrecht, NL: Kluwer Academic.

Roberts, B. W., Donnellan, M. B., \& Hill, P. L. (2012). Personality trait development in adulthood: Findings and implications. In I. B. Weiner, H. Tennen, \& J. M. Suls (Eds.), Handbook of Psychology. Volume 5: Personality and Social Psychology. New York: Wiley.

Roberts, B. W., Edmonds, G., \& Grijalva, E. (2010). It is developmental me, not generation me: Developmental changes are more important than generational changes in narcissismCommentary on Trzesniewski \& Donnellan (2010). Perspectives on Psychological Science, 5, 97-102.

Roberts, B. W., \& Nickel, L. B. (2017). A critical evaluation of the Neo-Socioanalytic Model of personality. In J. Specht (Ed.), Personality Development Across the Lifespan (pp. 157177). San Diego, CA: Elsevier. 
Roberts, B. W., Walton, K. E., \& Viechtbauer, W. (2006). Patterns of mean-level change in personality traits across the life course: A meta-analysis of longitudinal studies. Psychological Bulletin, 132, 1-25.

Roberts, B. W., \& Wood, D. (2006). Personality development in the context of the neosocioanalytic model of personality. In D. K. Mroczek \& T. D. Little (Eds.), Handbook of personality development. Mahwah, New Jersey: Lawrence Erlbaum Associates.

Rogoza, R., Wyszyńska, P., Maćkiewicz M., \& Cieciuch, J. (2016). Differentiation of the two narcissistic faces in their relation to personality traits and basic values. Personality and Individual Differences, 95, 85-88.

Specht, J., Egloff, B., \& Schmukle, S. C. (2011). Stability and change of personality across the life course: The impact of age and major life events on mean-level and rank-order stability of the Big Five. Journal of Personality and Social Psychology, 101, 862-882.

Stroh, L. K., Brett, J. M., \& Reilly, A. H. (1992). All the right stuff: a comparison of female and male managers' career progression. Journal of Applied Psychology, 77, 251-60.

Tasselli, S., Kilduff, M., \& Landis, B. (2018). Personality change: Implications for organizational behavior. The Academy of Management Annals, 12, 467-493.

Trzesniewski, K. H., Donnellan, M. B., \& Robins, R. W. (2008a). Do today's young people really think they are so extraordinary? An examination of secular trends in narcissism and selfenhancement. Psychological Science, 19, 181-188.

Trzesniewski, K. H., Donnellan, M. B., \& Robins, R. W. (2008b). Is "Generation Me" really more narcissistic than previous generations?. Journal of Personality, 76, 903-918.

Vergauwe, J., Wille, B., Hofmans, J., \& De Fruyt, F. (2017). Development of a Five-Factor Model charisma compound and its relations to career outcomes. Journal of Vocational Behavior, 99, 24-39. 
Wales, W. J., Patel, P. C., \& Lumpkin, G. T. (2013). In pursuit of greatness: CEO narcissism, entrepreneurial orientation, and firm performance variance. Journal of Management Studies, 50, 1041-1069.

Wallace, H. M., \& Baumeister, R. F. (2002). The performance of narcissists rises and falls with perceived opportunity for glory. Journal of Personality and Social Psychology, 82, 819834.

Watts, A. L., Lilienfeld, S. O., Smith, S. F., Miller, J. D., Campbell, W. K., Waldman, I. D., . . Faschingbauer, T. J. (2013). The double-edged sword of grandiose narcissism: Implications for successful and unsuccessful leadership among U.S. presidents. Psychological Science, 24, 2379-2389.

Wille, B., Beyers, W., \& De Fruyt, F. (2012). A transactional approach to person-environment fit: Reciprocal relations between personality development and career role growth across young to middle adulthood. Journal of Vocational Behavior, 81, 307-321.

Wille, B., \& De Fruyt, F. (2014). Vocations as a source of identity: Reciprocal relations between big five personality traits and RIASEC characteristics over 15 years. Journal of Applied Psychology, 99, 262-281.

Wille, B., De Fruyt, F., \& De Clercq, B. (2013). Expanding and reconceptualizing aberrant personality at work: Validity of five-factor model aberrant personality tendencies to predict career outcomes. Personnel Psychology, 66, 173-223.

Wille, B., De Fruyt, F., \& Feys, M. (2010). Vocational interests and big five traits as predictors of job instability. Journal of Vocational Behavior, 76, 547-558.

Wille, B., De Fruyt, F., \& Feys, M. (2013). Big Five traits and intrinsic success in the new career era: A 15 year longitudinal study on employability and work-family conflict. Applied Psychology: An International Review, 62, 124-156. 
Wille, B., Hofmans, J., Feys, M., \& De Fruyt, F. (2014). Maturation of work attitudes: Correlated change with big five personality traits and reciprocal effects over 15 years. Journal of Organizational Behavior, 35, 507-529.

Wood, D., \& Roberts, B. W. (2006). Cross-sectional and longitudinal tests of the Personality and Role Identity Structural Model (PRISM). Journal of Personality, 74, 779-809.

Woods, S. A., Lievens, F., De Fruyt, F., \& Wille, B. (2013). Personality across working life: The longitudinal and reciprocal influences of personality on work. Journal of Organizational Behavior, 34, 7-25.

Woods, S. A., Wille, B., Wu, C. H., Lievens, F., \& De Fruyt, F. (2019). The influence of work on personality trait development: The Demands-Affordances TrAnsactional (DATA) model, an integrative review, and research agenda. Journal of Vocational Behavior, 110, 258271.

Wright, A. G. C., \& Edershile, E. A. (2018). Issues resolved and unresolved in pathological narcissism. Current Opinion in Psychology, 21, 74-79.

Wrzus, C., \& Roberts, B. W. (2017). Processes of personality development in adulthood: The TESSERA framework. Personality and Social Psychology Review, 21, 253-277.

Yuan, Y., \& MacKinnon, D. P. (2009). Bayesian mediation analysis. Psychological Methods, 14, 301-322.

Zhu, D. H., \& Chen, G. (2015). Narcissism, director selection, and risk-taking spending. Strategic Management Journal, 36, 2075-2098.

Zyphur, M. J., and Oswald, F. L. (2013). Bayesian probability and statistics in management research: a new horizon. Journal of Management, 39, 5-13. 
Zyphur, M. J., \& Oswald, F. L. (2015). Bayesian estimation and inference: A user's guide.

Journal of Management, 41, 390-420. 
Table 1

Correlations between all study variables

\begin{tabular}{lccccccc}
\hline & $M$ & $S D$ & $n$ & 1 & 2 & 3 & 4 \\
\hline 1. Narcisism $_{\mathrm{T} 1}$ & 2.70 & .25 & 933 & - & & & \\
2. Narcisism $\mathrm{T} 2$ & 2.69 & .25 & 366 & $.60^{* * *}$ & - & & \\
3. Narcisism $\mathrm{T} 3$ & 2.64 & .24 & 293 & $.50^{* * *}$ & $.79^{* * *}$ & - & \\
4. Managerial level & 1.07 & 1.14 & 241 & $.14^{*}$ & $.29^{* * *}$ & $.30^{* * *}$ & - \\
5. Managerial level & 1.28 & 1.28 & 335 & $.17^{* *}$ & $.29^{* * *}$ & $.27^{* * *}$ & $.68^{* * *}$ \\
\hline
\end{tabular}

Note. T1 = 1994; T2 = 2009; T3 = 2016. ${ }^{*} p<05 ;{ }^{* *} p<01 ;{ }^{* * *} p<001$. 
Table 2

Summary of parameters estimated in the extended latent difference score model

Parameter Description estimate 95\% Hypothesis

CI

\section{Upper half of the model: Latent changes in Narcissism (N)}

Parameters capturing dynamics across the entire time frame

\begin{tabular}{|c|c|c|c|}
\hline Intercept $\left(I_{N}\right)$ & $\begin{array}{l}\text { Inter-individual differences in narcissism at the } \\
\text { start of the study interval }\end{array}$ & 2.70 & $\begin{array}{l}{[2.68} \\
2.72]\end{array}$ \\
\hline Slope $\left(S_{N}\right)$ & $\begin{array}{l}\text { Linear rate of intraindividual change in narcissism } \\
\text { across the entire study interval }\end{array}$ & .09 & $\begin{array}{l}{[-.04} \\
.21]\end{array}$ \\
\hline$\rho_{I N, S N}$ & $\begin{array}{l}\text { Correlation between narcissism intercept and } \\
\text { narcissism slope }\end{array}$ & -.45 & $\begin{array}{l}{[-.56,-} \\
.32]\end{array}$ \\
\hline \multicolumn{4}{|c|}{ Parameters capturing time-sequential dynamics (from one time period to the other) } \\
\hline $\begin{array}{l}\text { Proportional } \\
\text { change }\left(\beta_{N}\right)\end{array}$ & $\begin{array}{l}\text { The effect of narcissism at Time } \mathrm{T} \text { on subsequent } \\
\text { change in narcissism at Time } \mathrm{T}+1\end{array}$ & -.04 & $\begin{array}{l}{[-.08} \\
.01]\end{array}$ \\
\hline $\begin{array}{l}\text { Dual change } \\
\left(\phi_{N}\right)\end{array}$ & $\begin{array}{l}\text { The effect of change in narcissism } \mathrm{T} 1 \rightarrow \mathrm{T} 2 \text { on } \\
\text { change in narcissism } \mathrm{T} 2 \rightarrow \mathrm{T} 3\end{array}$ & -.76 & $\begin{array}{l}{[-.90,-} \\
.61]\end{array}$ \\
\hline
\end{tabular}

Lower half of the model: Latent changes in Managerial Level (ML)

Parameters capturing dynamics across the entire time frame

Slope $\left(S_{M L}\right) \quad$ Linear rate of intraindividual change in managerial $\quad .82 \quad[.69$, level across the entire study interval

Parameters capturing time-sequential dynamics (from one time period to the other)

Dual / The effect of change in managerial level $\mathrm{T} 1 \rightarrow \mathrm{T} 2 \quad-.53 \quad[-.68,-$

Proportional on change in managerial level $\mathrm{T} 2 \rightarrow \mathrm{T} 3$

change $\left(\phi_{M L}\right)$

\section{Coupling parameters linking Narcissism to Managerial Level over time}

Interrelations between $N$ and $M L$ across the entire time frame 
$\rho_{S N, S M L} \quad$ Correlation between narcissism slope and

$.35[.19$,

H1

managerial level slope

$\rho_{I N, S M L}$

Correlation between narcissism intercept and slope

.17

$[.05$,

$\mathrm{H} 2$

of managerial level

Time-sequential interrelations between $N$ and $M L$

Proportional The effect of narcissism at Time $\mathrm{T}$ on subsequent

$.03 \quad[.01$,

$\mathrm{H} 2$

change $\gamma_{N}$ change in managerial level at Time $\mathrm{T}+1$

.09]

Dual change $\left(\zeta_{N}\right)$ The effect of change in narcissism $\mathrm{T} 1 \rightarrow \mathrm{T} 2$ on

$-.58 \quad[-.94$,

$\mathrm{H} 2$ change in managerial level T2 $\rightarrow \mathrm{T} 3$

Dual /

The effect of managerial level at $(\mathrm{T} 1 \rightarrow) \mathrm{T} 2$ on

$-.04[-.06,-$

H3

Proportional change in narcissism T2 $\rightarrow \mathrm{T} 3$

$.02]$

change $\left(\zeta_{M L}\right)$

Note. Except for the correlations, all parameter estimates are unstandardized coefficients in this modeling framework. 


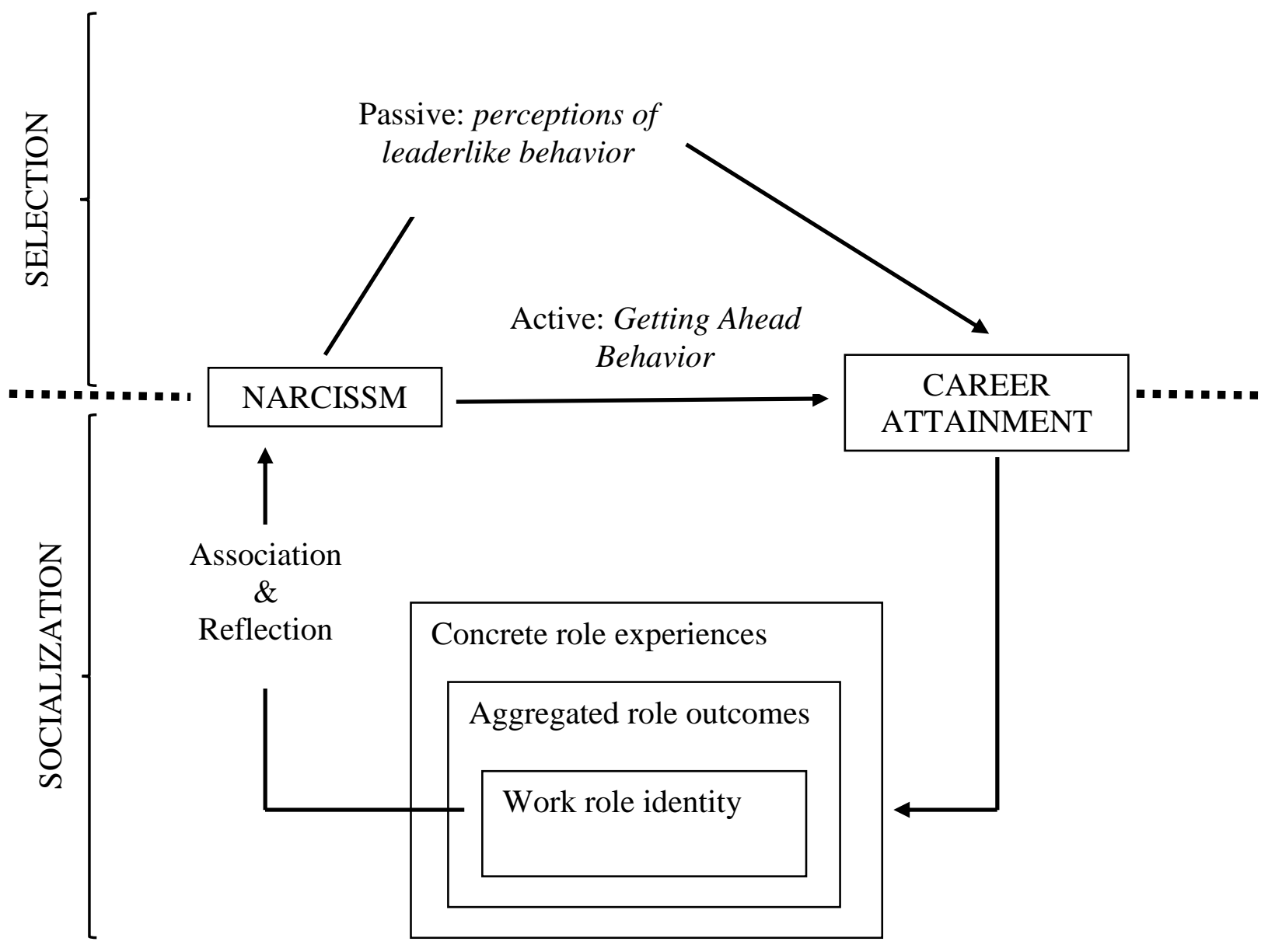

Figure 1. The bidirectional perspective on narcissism and career attainment. 


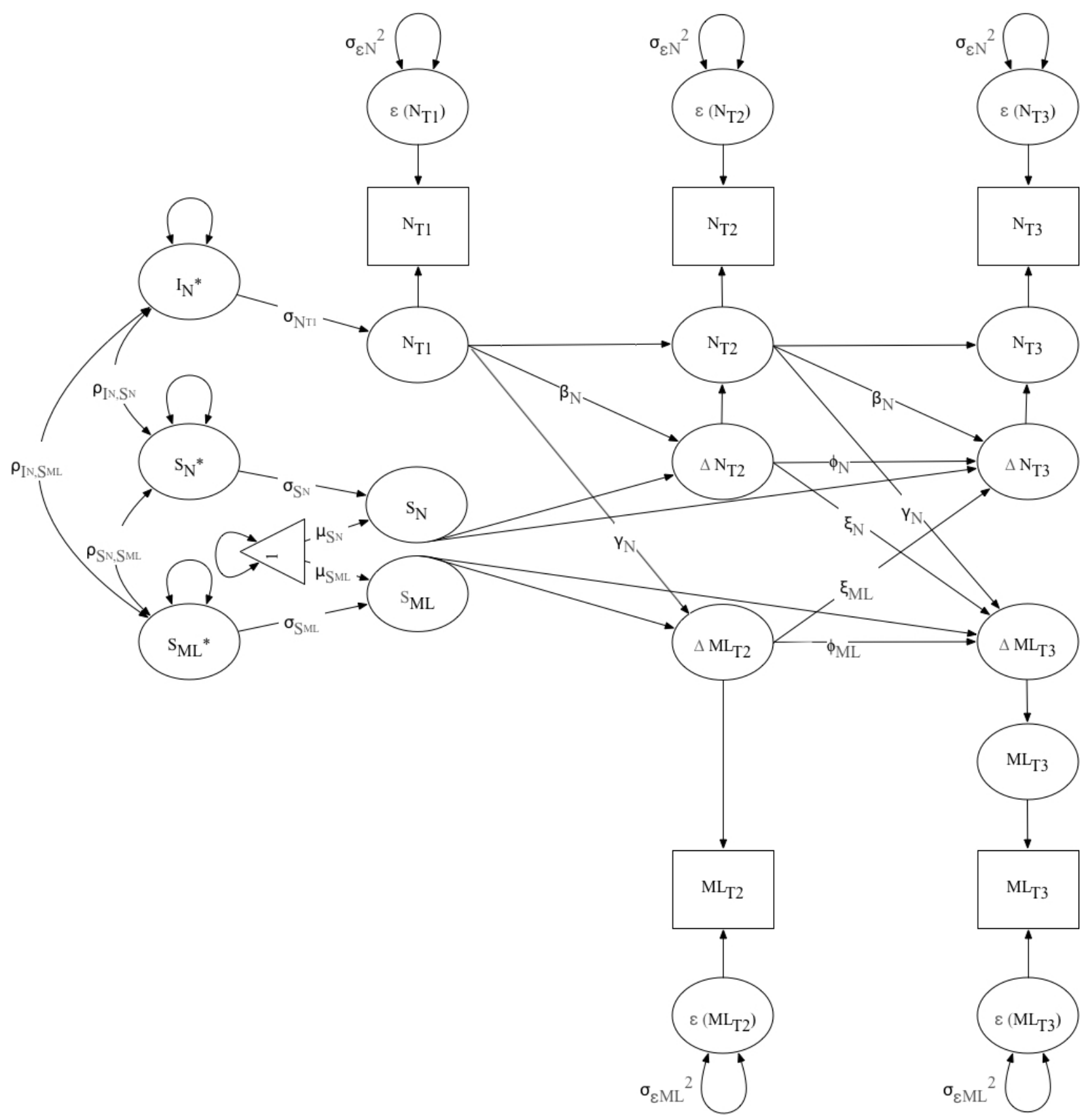

Figure 2. The extended latent change model connecting levels and changes in narcissism (upper half) to levels and changes in managerial level (lower half). Unlabeled paths are fixed equal to one, whereas parameters with the same label (i.e., $\Upsilon_{N}, \beta_{N}$ ) are constrained to be equal over time. 
Table A1

Appendix

Overview of the NEO PI-R facets included in the narcissistic count score

\begin{tabular}{ll}
\hline NEO PI-R facet & Manifestation \\
\hline A5(R): Low Modesty & Arrogance, grandiosity and conceit \\
A3(R): Low Altruism & Self-centeredness, selfishness and exploitation \\
A6(R): Low Tender-Mindedness & Lack of empathy \\
A2(R): Low Straightforwardness & Manipulativeness \\
A1(R): Low Trust & Tendency toward suspiciousness \\
A4(R): Low Compliance & Uncooperativeness \\
N2: High Angry Hostility & Tendency to become enraged (e.g., when criticized) \\
N4(R): Low Self-Consciousness & Absence of feelings of embarrassment \\
E1(R): Low Warmth & Formal, reserved and distant in manner \\
E3: High Assertiveness & Dominance and forcefulness \\
E5: High Excitement-Seeking & Craving for excitement and stimulation \\
O3(R): Low Openness to Feelings & Muted affects \\
O4: High Openness to Actions & Preference for novelty and variety \\
\hline
\end{tabular}

Note. (R) indicates that the facet must be reverse scored before the count score is computed. 


\section{Table A2}

\section{CFA-models testing measurement invariance across time}

\begin{tabular}{ll}
\hline MODEL & Agreeableness 1
\end{tabular}

1. Configural Invariance

Agreeableness 1

2. Invariance of the factor loadings

3. Invariance of the item intercepts

3a. Partial Invariance of the item intercepts - Model $3+\tau_{4 t 1}$ free

3b. Partial Invariance of the item intercepts - Model $3 a+\tau_{5 t 1}$ free

$3 c$. Partial Invariance of the item intercepts - Model $3 b+\tau_{2 t 1}$ free

Agreeableness 2

1. Configural Invariance

2. Invariance of the factor loadings

3. Invariance of the item intercepts

3a. Partial Invariance of the item intercepts - Model $3+\tau_{4 t 1}$ free

Agreeableness 3

1. Configural Invariance

$X^{2}$
$d f$ $p$ CFI RMSEA

$\begin{array}{lllll}454.36 & 225 & <.001 & .941 & .033 \\ 472.72 & 239 & <.001 & .940 & .032 \\ 591.20 & 252 & <.001 & .913 & .038 \\ 548.05 & 251 & <.001 & .924 & .036 \\ 506.95 & 250 & <.001 & .934 & .033 \\ 487.97 & 249 & <.001 & .939 & .032\end{array}$

2. Invariance of the factor loadings

2a. Partial Invariance of the factor loadings - Model $2+\lambda_{7 t 1}$ free

3. Invariance of the item intercepts

3a. Partial Invariance of the item intercepts - Model $3+\tau_{4 t 1}$ free

3a. Partial Invariance of the item intercepts - Model $3 a+\tau_{2 t 1}$ free

$\begin{array}{lllll}303.31 & 225 & <.001 & .976 & .019 \\ 322.42 & 239 & <.001 & .975 & .019 \\ 367.03 & 252 & <.001 & .965 & .022 \\ 336.34 & 251 & <.001 & .974 & .019\end{array}$

1. Configural Invariance

Agreeableness 4

2. Invariance of the factor loadings

3. Invariance of the item intercepts

3a. Partial Invariance of the item intercepts - Model $3+\tau_{8 t 1}$ free

$\begin{array}{lllll}509.13 & 225 & <.001 & .885 & .037 \\ 529.74 & 239 & <.001 & .882 & .036 \\ 526.54 & 238 & <.001 & .883 & .036 \\ 563.86 & 251 & <.001 & .873 & .037 \\ 554.31 & 250 & <.001 & .877 & .036 \\ 543.23 & 249 & <.001 & .881 & .036\end{array}$

1. Configural Invariance

Agreeableness 5

2. Invariance of the factor loadings

3. Invariance of the item intercepts

3a. Partial Invariance of the item intercepts - Model $3+\tau_{3 t 1}$ free

$3 b$. Partial Invariance of the item intercepts - Model $3 a+\tau_{5 t 1}$ free

$3 c$. Partial Invariance of the item intercepts - Model $3 b+\tau_{8 t 1}$ free

$\begin{array}{lllll}326.51 & 225 & <.001 & .950 & .022 \\ 344.07 & 239 & <.001 & .948 & .022 \\ 449.33 & 252 & <.001 & .903 & .029 \\ 361.77 & 251 & <.001 & .946 & .022\end{array}$

1. Configural Invariance

Agreeableness 6

2. Invariance of the factor loadings

3. Invariance of item intercepts

3a. Partial Invariance of the item intercepts - Model $3+\tau_{7 t 1}$ free

$3 b$. Partial Invariance of the item intercepts - Model $3 a+\tau_{6 t 1}$ free

$3 c$. Partial Invariance of the item intercepts - Model $3 b+\tau_{8 t 1}$ free

$3 d$. Partial Invariance of the item intercepts - Model $3 c+\tau_{4 t 1}$ free

$\begin{array}{ccccc}887.19 & 225 & <.001 & .807 & .056 \\ 902.85 & 239 & <.001 & .806 & .055 \\ 1046.38 & 252 & <.001 & .768 & .058 \\ 1004.33 & 251 & <.001 & .780 & .057 \\ 973.77 & 250 & <.001 & .789 & .056 \\ 920.06 & 249 & <.001 & .804 & .054\end{array}$

$\begin{array}{lllll}387.72 & 225 & <.001 & .921 & .028 \\ 402.89 & 239 & <.001 & .920 & .027 \\ 483.53 & 252 & <.001 & .887 & .031 \\ 451.01 & 251 & <.001 & .903 & .029 \\ 434.74 & 250 & <.001 & .910 & .028 \\ 419.51 & 249 & <.001 & .917 & .027 \\ 412.60 & 248 & <.001 & .920 & .027\end{array}$

1. Configural Invariance

Extraversion 1

2. Invariance of the factor loadings

536.72

225

$<.001 \quad .896$

.039

544.12

239

$<.001 \quad .898$

.037

$\begin{array}{lllll}734.18 & 252 & <.001 & .839 & .045\end{array}$

3a. Partial Invariance of the item intercepts - Model $3+\tau_{3 t 1}$ free

646.57

$251<.001 \quad .868$

.041 
3b. Partial Invariance of the item intercepts - Model $3 \mathrm{a}+\tau_{4 t 1}$ free 3c. Partial Invariance of the item intercepts - Model $3 b+\tau_{6 t 1}$ free 3d. Partial Invariance of the item intercepts - Model $3 c+\tau_{8 t 1}$ free 3e. Partial Invariance of the item intercepts - Model $3 d+\tau_{3 t 2}$ free

Extraversion 3

1. Configural Invariance

2. Invariance of the factor loadings

3. Invariance of the item intercepts 3a. Partial Invariance of the item intercepts - Model $3+\tau_{5 t 1}$ free 3b. Partial Invariance of the item intercepts - Model $3 \mathrm{a}+\tau_{7 t 1}$ free $3 c$. Partial Invariance of the item intercepts - Model $3 b+\tau_{4 t 1}$ free

Extraversion 5

1. Configural Invariance

2. Invariance of the factor loadings

3. Invariance of the item intercepts

3a. Partial Invariance of the item intercepts - Model $3+\tau_{4 t 1}$ free 3b. Partial Invariance of the item intercepts - Model $3 \mathrm{a}+\tau_{7 t 1}$ free 3c. Partial Invariance of the item intercepts - Model $3 b+\tau_{5 t 1}$ free $3 d$. Partial Invariance of the item intercepts - Model $3 c+\tau_{6 t 1}$ free

Neuroticism 2

1. Configural Invariance

2. Invariance of the factor loadings

3. Invariance of the item intercepts

3a. Partial Invariance of the item intercepts - Model $3+\tau_{2 t 1}$ free 3b. Partial Invariance of the item intercepts - Model $3 a+\tau_{7 t 1}$ free 3c. Partial Invariance of the item intercepts - Model $3 b+\tau_{6 t 1}$ free $3 \mathrm{~d}$. Partial Invariance of the item intercepts - Model $3 \mathrm{c}+\tau_{8 t 1}$ free 3e. Partial Invariance of the item intercepts - Model $3 d+\tau_{5 t 2}$ free

Neuroticism 4

1. Configural Invariance

2. Invariance of the factor loadings

2a. Partial Invariance of the factor loadings - Model $2+\lambda_{2 t 1}$ free

3. Invariance of the item intercepts

3a. Partial Invariance of the item intercepts - Model $3+\tau_{2 t 1}$ free

$3 \mathrm{~b}$. Partial Invariance of the item intercepts - Model $3 \mathrm{a}+\tau_{6 t 1}$ free

$3 c$. Partial Invariance of the item intercepts - Model $3 b+\tau_{3 t 1}$ free

Openness 3

1. Configural Invariance

2. Invariance of the factor loadings

3. Invariance of the item intercepts

3a. Partial Invariance of the item intercepts - Model $3+\tau_{8 t 1}$ free 3b. Partial Invariance of the item intercepts - Model $3 \mathrm{a}+\tau_{4 t 1}$ free 3c. Partial Invariance of the item intercepts - Model $3 b+\tau_{7 t 1}$ free $3 d$. Partial Invariance of the item intercepts - Model $3 c+\tau_{2 t 1}$ free

Openness 4

1. Configural Invariance

2. Invariance of the factor loadings

3. Invariance of the item intercepts

3a. Partial Invariance of the item intercepts - Model $3+\tau_{6 t 1}$ free

$\begin{array}{lllll}609.45 & 250 & <.001 & .880 & .039 \\ 573.14 & 249 & <.001 & .892 & .037 \\ 562.62 & 248 & <.001 & .895 & .037 \\ 555.21 & 247 & <.001 & .897 & .037\end{array}$

\subsection{5}

550.87

691.24

593.88

574.33

563.92

225

239

252

251

250

249

$<.001 \quad .933$

$<.001 \quad .931$

$<.001 \quad .902$

$<.001 \quad .924$

$<.001 \quad .928$

$<.001 \quad .930$

.038

.037

.043

.038

.037

.037

380.30

399.23

225

$<.001$

.939

.027

239

$<.001$

.937

.027

494.86

252

$<.001$

.905

450.72

251

$<.001$

.922

.032

.029

426.47

250

$<.001$

.931

.028

418.25

249

$<.001 \quad .934$

.027

409.35

$248<.001 \quad .937$

.026

539.48

547.55

225

239

$<.001$

.901

.039

752.26

25

$<.001$

.903

632.64

251

$<.001 \quad .843$

.037

602.60

250

$<.001$

.880

.046

585.69

249

$<.001$

.040

567.51

248

$<.001$

.889

.039

$<.001$

.894

.038

561.70

247

$<.001$

.901

.037

.037

289.79

225

$<.001$

.976

.018

523.53

239

$<.001$

.896

.036

303.16

238

$<.001$

.976

.017

488.58

251

$<.001$

.913

.032

410.54

250

$<.001$

.941

.026

333.60

$<.001$

$<.001 \quad .977$

.019

310.15

248

.016

396.84

413.86

493.55

454.53

443.04

434.60

428.27

225

239

252

251

250

249

248
$<.001 \quad .933$

$<.001 \quad .932$

$<.001 \quad .906$

$<.001 \quad .921$

$<.001 \quad .925$

$<.001 \quad .928$

$<.001 \quad .930$

396.47

409.88

538.98

484.12
225

239

252

251
$<.001 \quad .930$

$<.001 \quad .930$

$<.001 \quad .882$

$<.001 \quad .904$
.029

.028

.032

.029

.029

.028

.028 
3b. Partial Invariance of the item intercepts - Model $3 a+\tau_{7 t 1}$ free

433.91

250

$<.001$

.924

.028

$3 C$. Partial Invariance of the item intercepts - Model $3 b+\tau_{4 t 1}$ free

423.62

$\begin{array}{lll}249 & <.001 \quad .928\end{array}$

.027

Note. CFI refers to the Comparative Fit Index, and RMSEA to the Root Mean Square Error of Approximation. 